NBER WORKING PAPERS SERIES

\title{
EMPIRICAL TESTING OF ASSET PRICING MODELS
}

Bruce N. Lehmann

Working Paper No. 4043

NATIONAL BUREAU OF ECONOMIC RESEARCH 1050 Massachusetts Avenue

Cambridge, MA 02138

April 1992

Prepared for the New Palgrave Dictionary of Money and Finance. Thanks are due to Ravi Jagannathan, David Modest, Arthur Warga, and, especially, Andrew Lo for many helpful comments. The usual disclaimer applies. This paper is part of NBER's research program in Asset Pricing. Any opinions expressed are those of the author and not those of the National Bureau of Economic Research. 
NBER Working Paper \#4043

April 1992

\title{
EMPIRICAL TESTTNG OF ASSET PRICING MODELS
}

\begin{abstract}
This essay reviews the extensive literature on empirical testing of asset pricing models. It briefly describes the kinds of asset pricing models typically tested in the literature and explicates their econometric implications, both in terms of the estimation of relevant parameters and tests of their implied restrictions. Pertinent aspects of the available data on security prices and macroeconomic variables are discussed as well. The essay concludes with the examination of selected aspects of the current empirical state of asset pricing theory.
\end{abstract}

Bruce N. Lehmann

Graduate School of International Relations and Pacific Studies University of California, San Diego

La Jolla, CA 92093 and NBER 
The content and style of both theoretical and empirical research on the pricing of capital assets has changed dramatically during the last three decades. Prior research in finance typically involved valuation exercises for individual securities considered in isolation-what would usually be termed security analysis-using empirical principles derived from corporate finance and financial accounting. Modern theory emphasizes the implications of comovements among security returns for the valuation that investors should place on individual securities. Similarly, modern empirical research has been largely devoted to the collection of facts regarding regularities in security prices across assets and time with which to confront the theory.

Financial economics retained a sharp empirical focus throughout this transition. Empirical work is far more prominent in finance than in other branches of economics. In part, this reflects the availability of high quality data on many relevant variables-stock prices, dividends, bond yields, and the like. However, it is also a consequence of other factors like the focus of earlier research on the valuation of actual securities, the modern theoretical emphasis on models couched in terms of potential observables, their practical usefulness, 
and the ability to assess the success or failure of models by the common measuring rod of financial profit and loss. Feedback between theory and fact has led to much scientific progress in the study of asset prices.

This entry is devoted largely to the elucidation of the methodological aspects of this successful interplay between theoretical and empirical research. The next section describes the kinds of asset pricing models typically tested in the literature and sketches their econometric implications. The subsequent section describes the methods used to estimate and test models while the penultimate section discusses relevant aspects of available data on security prices. The final section surveys selected aspects of the current empirical state of asset pricing theory and provides some brief concluding remarks.

\section{Modern Asset Pricing Theory}

That one can write a reasonably coherent self-contained essay on empirical tests of asset pricing theory (as opposed to a disjointed survey of loosely connected topics) is largely a testament to the communalities among alternative models. The central elements of modern theory are the specification of the economic environment confronting investors and the twin behavioral assumptions that investors exploit any arbitrage 
opportunities and that they have rational expectations about future prospects. This section describes the asset pricing models that emerge in this setting.

The principal environmental assumption is that investors confront perfect markets-the absence of frictions like taxes, transactions costs, and constraints on short sales. While there are models that permit some frictions, they are often either intractable or bear a striking resemblance to perfect markets models. For example, tax-based or proportional transactions cost asset pricing models often look like after-tax or transactions cost adjusted versions of frictionless models.

The central behavioral assumption is that of investor rationality in two dimensions. The first dimension is the no free lunch assumption-that security prices do not permit investors to perceive any arbitrage opportunities. The premise that rational investors would vigorously exploit any arbitrage opportunities is the closest thing to physical force in financial economics. Following Rubinstein(1976) and Ross(1978), the noarbitrage value of an arbitrary uncertain income stream is:

$$
P_{i t}=\sum_{j=1}^{\infty} E^{*}\left[d_{i t+j} Q_{t, j} \mid I_{t}\right] ; Q_{t, j}>0 \forall t, j>0
$$

where $d_{i t+j}$ represents income received from security $i$ at time 
$t+j, P_{i t}$ is the price of a claim to this income stream, $Q_{t, j}$ is the state price density (giving state prices per unit probability or probability-adjusted shadow prices), the expectations operator $E^{*}\left[\bullet \mid I_{t}\right]$ reflects probability beliefs, which need not be rational or objective, held conditional on information available at time $\mathbf{t}$ (i.e., $\mathrm{L}_{\mathrm{t}}$ ), and the information set and probability beliefs can differ across investors. Different values of $Q_{t, j}$ (which are generally not unique in incomplete markets) are implied by different probability beliefs.

The second behavioral assumption is that investors possess rational expectations or objective probability beliefs. In these circumstances:

$$
P_{i t}=\sum_{j=1}^{\infty} E\left[d_{i t+j} Q_{t, j} \mid I_{t}\right] ; Q_{t, j}>0 \forall t, j>0
$$

where $\mathrm{E}\left[\bullet \mid \mathrm{I}_{\mathrm{t}}\right]$ represents the population conditional expectation of its argument so that $E\left[\bullet \mid I_{t}\right]$ equals $E^{*}\left[\bullet \mid I_{t}\right]$ above. Behavioral rationality in both dimensions is the defining characteristic of the efficient markets hypothesis.

Simple ideas underlie this abstract present value relation. The set of strictly positive random variables $Q_{t, j}$ exists if it is not possible to form costless (zero net investment or selffinancing) portfolios that earn riskless positive profits. In terms 
of conventional constructs like the means and variances of returns, the pricing relation simply implies that investors face a finite tradeoff between mean and variance.

Straightforward translations of this relation yield familiar models. For example, the stochastic assumption:

$$
\left.E\left[d_{i t+j} Q_{t, j} \mid L_{t}\right]=E\left[d_{i t+j} \mid L_{t}\right]^{\left(1+r_{i}\right.}\right)^{j}
$$

yields the famous martingale model in which returns are unpredictable save for their constant means. Similarly, $Q_{t, j}$ is the representative investor's marginal rate of substitution in consumption between periods $t$ and $t+j$ adjusted for inflation in most equilibrium models.

In order to explicate the econometric implications of this class of models, it is useful to translate the model into an expression for single period returns. Trivial algebraic manipulation of the present value relation yields:

$$
E\left[R_{i t+1} Q_{t, 1} \mid L_{t}\right]=E\left[\frac{P_{i t+1}+d_{i t+1}}{P_{i t}} Q_{t, 1} \mid L_{t}\right]=1
$$

Some empirical researchers work with prices and the general present value relation or multiperiod returns but the bulk of the literature studies single period returns. Accordingly, the remainder of the essay will be confined to the analysis of returns.

It is also useful to rewrite these models in a more 
standard form-'beta' pricing models in which (conditional) expected returns are linearly related to the (conditional) coefficients (i.e., betas) from the regression of returns on particular portfolios. Following Hansen and Jagannathan(1990), consider the projection:

$$
\mathrm{Q}_{\mathrm{t}, 1}=\psi_{\mathrm{t}, 1}+\theta_{\mathrm{t}, 1} \mathrm{R}_{\mathrm{pt}+1}+\varepsilon_{\mathrm{Qt}+1} ; \quad \mathrm{E}\left[\mathrm{R}_{\mathrm{pt+1}} \varepsilon_{\mathrm{Qt}+1} \mid \mathrm{L}_{\mathrm{t}}\right]=0
$$

where $R_{p t+1}$-a portfolio based on the arbitrary menu of $N$ assets with return vector $\underline{R}_{t+1}$-replicates the risk/return characteristics of $Q_{t, 1}$. The return $R_{p t+1}$ provides a scale-free proxy for $\mathrm{Q}_{\mathrm{t}, 1}$. Portfolios like $\mathrm{p}$ have returns that are maximally correlated with $Q_{t, 1}$ and weights proportional to $\operatorname{Var}\left[\mathbb{R}_{t+1} / I_{t}\right]^{-1} \operatorname{Cov}\left[\mathbb{R}_{t+1}, Q_{t, 1} \mid I_{t}\right]$ (where $\operatorname{Var}[\bullet]$ and $\operatorname{Cov}[\bullet]$ denote the variance and covariance of their arguments, respectively) since $E\left[R_{i t+1} Q_{t, 1} \mid I_{t}\right]$ equals one. All portfolios $z$ with returns $R_{z t+1}$ uncorrelated with $Q_{t, 1}$ and portfolio $p$ have conditional expected return $E\left[Q_{t, 1} \mid L_{4}\right]^{-1}$.

Accordingly, $\mathrm{Q}_{\mathrm{t}, 1}$ satisfies the projection equation:

$$
\begin{gathered}
\mathrm{Q}_{\mathrm{t}, 1}=E\left[R_{\mathrm{zt}+1} \mid \mathrm{L}_{\mathrm{t}}\right]^{-1}\left[1-\frac{\mathrm{E}\left[\mathrm{R}_{\mathrm{pt}+1^{-}}-R_{\mathrm{zt}+1} \mid \mathrm{I}_{\mathrm{t}}\right]}{\operatorname{Var}\left[R_{\mathrm{pt}+1} \mid \mathrm{I}_{\mathrm{t}}\right]}\left(R_{\mathrm{pt}+1}-E\left[R_{\mathrm{pt}+1} \mid \mathrm{I}_{\mathrm{t}}\right)\right]\right. \\
+\varepsilon_{\mathrm{Qt}+1}
\end{gathered}
$$

which provides an obvious identification of $\psi_{t, 1}$ and $\theta_{t, 1}$. Rewriting the expected return relation in terms of portfolios $p$ and $\mathrm{z}$ yields: 


$$
\begin{gathered}
\underline{R}_{t+1}=1 E\left[R_{z t+1} \mid I_{t}\right]+\beta_{p t+1}\left(R_{p t+1}-E\left[R_{z t+1} \mid I_{t}\right]\right)+\varepsilon_{p t+1} ; \\
E\left[\varepsilon_{p t+1} \mid I_{t}\right]=\underline{0} ; \quad E\left[\varepsilon_{p t+1} \varepsilon_{p t+1} \mid I_{t}\right]=\Sigma_{p t+1} ; \\
\beta_{p t+1}=\operatorname{Cov}\left[\underline{R}_{t+1}, R_{p t+1} \mid I_{t}\right] / \operatorname{Var}\left[R_{p t+1} \mid I_{t}\right]
\end{gathered}
$$

A portfolio $\mathrm{p}$ which implies a linear risk/return relation like this is said to be conditionally mean-variance efficient. Two restrictions are lost in the passage from a priori knowledge of

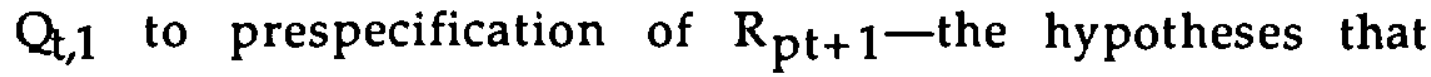
$E\left[R_{z t+1} \mid I_{t}\right]$ equals $E\left[Q_{t, 1} \mid I_{t}\right]^{-1}$ for all portfolios with returns uncorrelated with $Q_{t, 1}$ and that $E\left[R_{p t+1} \mid I_{t}\right]$ equals $E\left[Q_{t, 1} \mid I_{t}\right]\left[1-\operatorname{Cov}\left(R_{p t+1}, Q_{t, 1} \mid I_{t}\right)\right]$. This occurs because the return $R_{p t+1}$ is scale-free like an index number.

Asset pricing models differ in their specification of the pricing operator $Q_{t, j}$ and the replicating portfolios $p$ and $z$. When one exists, the riskless asset can usually replace portfolio z. Table 1 lists a variety of mainstream asset pricing models, their postulated risk factors (i.e., sources of uncertainty underlying $Q_{t, j}$ ), and the portfolio $p$ that the model implies is (conditionally) mean-variance efficient (i.e., generates a linear risk/return relation). In this table, efficient means meanvariance efficient (i.e., minimizes variance for a given mean return). 
Table 1

\begin{tabular}{|c|c|c|}
\hline Model & $\begin{array}{l}\text { Postulated Risk } \\
\text { Factor(s) }\end{array}$ & Portfolio p \\
\hline $\begin{array}{l}\text { Capital Asset } \\
\text { Pricing Model } \\
\text { (CAPM) }\end{array}$ & Aggregate Wealth & $\begin{array}{c}\text { Market Portfolio of } \\
\text { All Risky Assets }\end{array}$ \\
\hline $\begin{array}{c}\text { Arbitrage Pricing } \\
\text { Theory (APT) }\end{array}$ & $\begin{array}{l}\text { Common Factors } \\
\text { That Account for } \\
\text { Systematic } \\
\text { Correlation Among } \\
\text { Security Returns }\end{array}$ & $\begin{array}{c}\text { Efficient } \\
\text { Combination of } \\
\text { Factor Replicating } \\
\text { Portfolios }\end{array}$ \\
\hline $\begin{array}{c}\text { Intertemporal } \\
\text { CAPM (ICAPM) }\end{array}$ & $\begin{array}{l}\text { Growth Rates of } \\
\text { State Variables } \\
\text { Including } \\
\text { Aggregate Wealth }\end{array}$ & $\begin{array}{c}\text { Efficient } \\
\text { Combination of } \\
\text { Market and State } \\
\text { Variable Hedge } \\
\text { Portfolios } \\
\end{array}$ \\
\hline $\begin{array}{c}\text { Consumption- } \\
\text { based CAPM } \\
\text { (CCAPM) }\end{array}$ & $\begin{array}{c}\text { Aggregate } \\
\text { Intertemporal } \\
\text { Marginal Utility } \\
\text { Functional }\end{array}$ & $\begin{array}{c}\text { Portfolio } \\
\text { Maximally } \\
\text { Correlated With } \\
\text { Marginal Utility } \\
\text { Functional }\end{array}$ \\
\hline $\begin{array}{c}\text { Continuous Time } \\
\text { CCAPM }\end{array}$ & $\begin{array}{l}\text { Instantaneous } \\
\text { Growth Rate of } \\
\text { Aggregate } \\
\text { Consumption }\end{array}$ & $\begin{array}{c}\text { Portfolio } \\
\text { Maximally } \\
\text { Correlated With } \\
\text { Aggregate } \\
\text { Consumption } \\
\text { Growth }\end{array}$ \\
\hline $\begin{array}{l}\text { CAPM With Non- } \\
\text { Traded Assets }\end{array}$ & $\begin{array}{l}\text { Aggregate Wealth } \\
\text { and Non-Traded } \\
\text { Asset Returns }\end{array}$ & $\begin{array}{c}\text { Efficient } \\
\text { Combination of } \\
\text { Market and } \\
\text { Portfolios } \\
\text { Maximally } \\
\text { Correlated With } \\
\text { Non-Traded Assets }\end{array}$ \\
\hline
\end{tabular}

Related models include a variety of international CAPMs and APTs as well as linear after-tax models. 
Finally, it is worth noting an important limitation of these models. Given observation of $\mathrm{Q}_{t, 1}$ or $\mathrm{R}_{\mathrm{pt+1}}$ and modest $a$ priori knowledge of the stochastic structure of returns, these models make precise predictions about capital asset prices. However, they make few predictions about quantities save for those that impinge on $Q_{t, 1}$ and for the trivial, and trivially false, predictions of no trade or portfolio separation that arise under representative investor assumptions. Good models of price behavior might be poor models of quantity behavior and, in particular, of the volume of trade, a problem that will occupy future research.

\section{Econometric Methods}

This no-arbitrage rational expectations asset pricing model implies a tight link between the economic and econometric characteristics of asset pricing theory. These asset pricing relations imply that the (conditional) expected value of $R_{i t+1} Q_{t, 1}$ is unity for all assets satisfying the perfect markets assumption if the underlying model is true. Intuitively, parameter estimation can proceed by analyzing sample analogues of this moment condition, which should be close to one in the neighborhood of the true parameter values. Similarly, the joint hypotheses of perfect markets, market 
efficiency, and the model for $Q_{t, 1}$ can be tested by measuring the proximity of these sample moment to unity.

What remains is to formalize this intuition. The remainder of this subsection discusses an important special case-the zero beta CAPM and the corresponding problem of testing the mean-variance efficiency of a given portfolio $\mathrm{p}$. In the zero beta CAPM, the model for returns is:

$$
\begin{array}{rr}
\underline{R}_{t+1}=\underline{l} R_{z}+\beta_{p}\left(R_{p t+1}-R_{z}\right)+\varepsilon_{p t+1} ; & E\left[R_{z t+1}-R_{z} \mid I_{t}\right]=\underline{0} ; \\
E\left[\varepsilon_{p t+1} \mid L_{t}\right]=\underline{0} ; & E\left[\varepsilon_{p t+1} \varepsilon_{p t+1} \mid I_{t}\right]=\Sigma_{p}
\end{array}
$$

and the unknown parameters are the expected return $R_{z}$ of portfolio $\mathrm{z}$, the vector of individual security betas $\mathfrak{\beta}_{\mathrm{p}}$, and the residual covariance matrix $\Sigma_{\mathrm{p}}$. This time invariant beta pricing model differs from the general no-arbitrage model in the time invariance constraints placed on $R_{z}, \beta_{p}$, and $\Sigma_{p}$ and the omission of the restrictions that $R_{z}$ equals $E\left[Q_{t, 1} \mid I_{t}\right]^{-1}$ and that $E\left[R_{p t+1} \mid I_{t}\right]$ equals $E\left[Q_{t, 1} \mid I_{t}\right]\left[1-\operatorname{Cov}\left(R_{p t+1}, Q_{t, 1} \mid L_{t}\right)\right]$.

This model provides a useful illustration even for multiple beta models like the APT or ICAPM or when portfolio $\mathrm{z}$ is identified a priori as when a freely traded riskless asset is assumed to exist. In these cases, simply interpret $\left(1-\beta_{p}\right)$ is the vector of betas on a second factor (ignoring the link with $\mathfrak{B}_{\mathrm{p}}$ ) or interpret all returns as excess returns over the observed riskless 
rate (so that $R_{z}$ equals zero). The extension to the case of more than two betas is straightforward. Similarly, the replacement of portfolio $\mathrm{p}$ by variables like the growth rate of aggregate consumption adds no new problems save for the need to estimate the associated consumption risk premium.

The passage from a priori specification of $\mathrm{Q}_{\mathrm{t}, 1}$ to a priori identification of portfolio $\mathrm{p}$ has greatly affected the focus of empirical research. The principal predictions of this time invariant beta pricing model are cross-sectional-that expected asset returns are linearly related to asset betas. Consequently, the empirical literature has focussed largely on the ability of cross-sectional variation in betas to account for cross-sectional variation in mean returns. To be sure, the model makes time series predictions-that all serial correlation in returns is mediated through $R_{p t+1}$ or, as is commonly assumed, that returns are unpredictable because $R_{p t+1}$ is assumed to be unpredictable. Nevertheless, until recently, the literature has concentrated on the question of whether these models can explain relative asset prices and not the level of asset prices or the market price of risk.

This is not to say that the overall level of asset prices is not an important research topic. The apparently high average 
excess return on equity securities over the riskfree rate-the market price of risk or equity premium-compared with the predictions of equilibrium models is generally referred to as the equity premium puzzle, although the extent of the puzzle remains in doubt since the equity premium is measured very imprecisely. Similarly, the apparently low return on nominally riskless assets is also inexplicable in current equilibrium models and is known as the riskfree rate puzzle. Still, relative asset prices have been the main preoccupation of the asset pricing literature.

Many of the relevant econometric issues can be illustrated geometrically for this time invariant beta pricing model. Figure 1 depicts three loci: the mean-variance efficient set (i.e., the set of all portfolios that minimize the variance of returns at each level of mean return), the set of all portfolios with returns orthogonal to the efficient portfolio $\mathrm{p}^{*}$ (i.e., the vertical line through $\mathrm{z}^{*}$ ), and the set of minimum variance portfolios with returns orthogonal to the inefficient portfolio p. All moments can be interpreted as either sample or population moments (or, for other purposes, as either conditional or unconditional moments). 
Figure 1

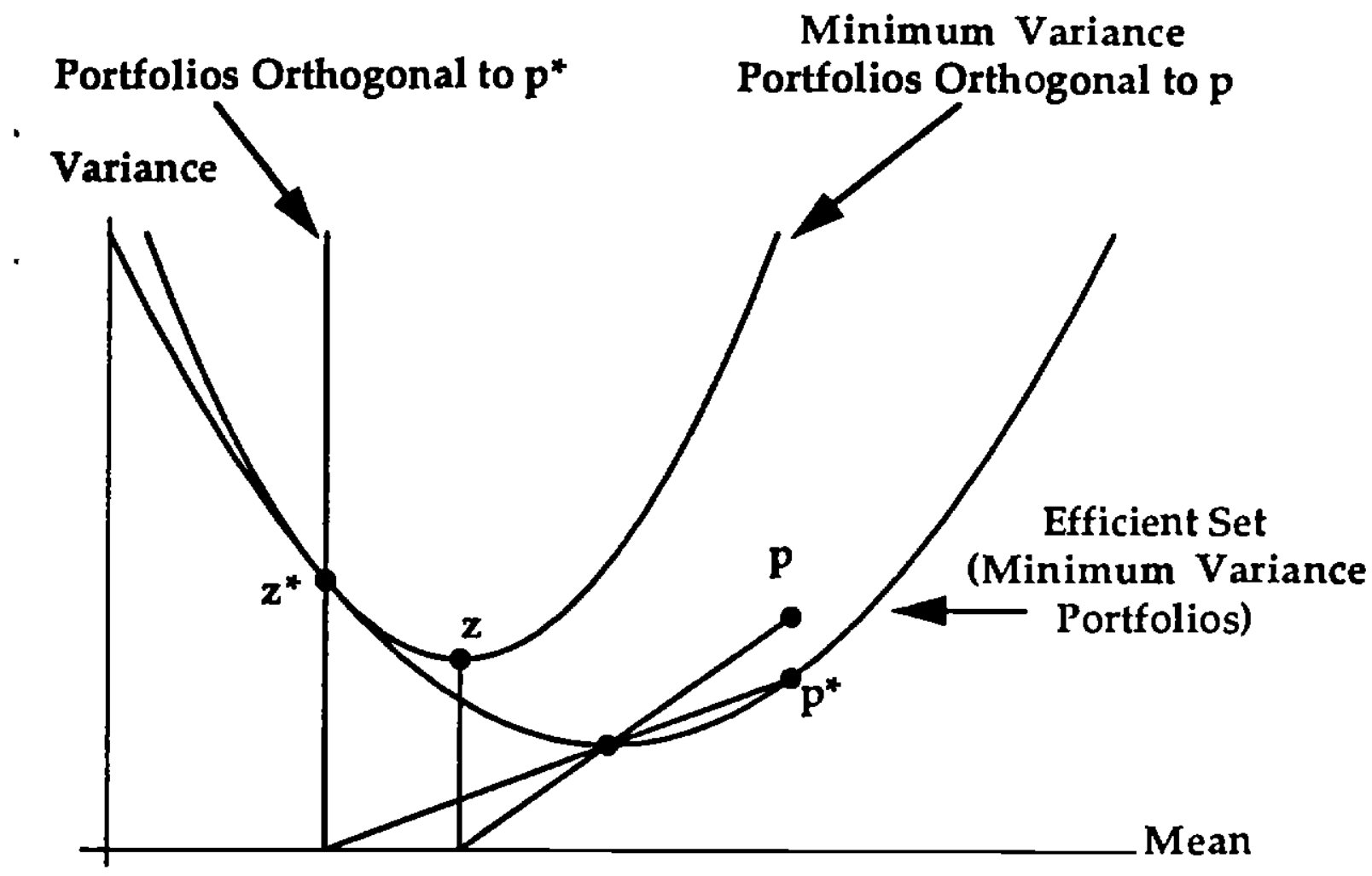

Estimation

Figure 1 illustrates the basic principles of estimation in time invariant asset pricing models. When the means and variances in Figure 1 represent sample moments, the efficient set gives the set of portfolios that are mean-variance efficient in the sample (i.e., ex post) and portfolio $\mathrm{p}$ is the portfolio whose ex ante efficiency is in question. In these circumstances, there are numerous portfolios with returns uncorrelated with those of portfolio $\mathrm{p}$ in the sample-the set of minimum variance portfolios with returns orthogonal to those of $p$ in the sample 
and all of the portfolios that lie inside this parabola. The mean return of each of these portfolios provides a consistent estimate of the zero beta rate $R_{z}$ when portfolio $p$ is ex ante efficient. In other words, the parabola of minimum variance orthogonal portfolios collapses to a line like $\mathrm{z}^{*}$ in large samples as $\mathrm{p}$ converges to a point like $\mathrm{p}^{*}$ since the sample efficient frontier converges to the population frontier.

Neither sample minimum variance frontier can be constructed when there are fewer time series observations than assets. The resulting sample covariance matrix of returns (the relevant second moments) is singular and, hence, noninvertible. Put differently, there are many portfolios with zero sample return variances in these circumstances. This problem pervades empirical asset pricing research.

The idea that one can estimate $R_{z}$ with the average return of a portfolio with weights based on sample moments was crucial for the formulation of estimation and inference procedures for linear asset pricing models. The portfolio interpretation has a simple source. We may not observe portfolio $\mathrm{z}$ but we typically observe or can estimate asset betas. Methods for estimating $R_{z}$ such as ordinary, weighted, or generalized least squares are linear statistical procedures and, 
hence, the least squares weights can be interpreted as portfolio weights. This general idea facilitated the development of risk premium estimators to cope with the small sample effects of a variety of potential measurement errors. In addition, the returns of these portfolios can be used to draw inferences about risk premium estimates.

Portfolio $z$ is an econometrically special portfolio-its mean return is the same as that produced by a generalized least squares regression. To fix notation, let $\underline{R}$ denote the vector of sample mean asset returns, let $\underline{b}_{p}$ denote their sample betas (i.e., the sample covariances of individual security returns with those of portfolio $\mathrm{p}$ divided by the sample variance of portfolio p), let $S_{p}$ denote the sample covariance matrix of the residuals from the regression yielding $\underline{b}_{p}$, let $R_{p}$ denote the sample mean return of portfolio $p$, let 1 denote a suitably conformable vector of ones, and let $\mathrm{T}$ denote the number of time series observations on asset returns. Cross-sectional regression estimators $r_{z}$ of the expected return $R_{z}$ take the form:

$$
r_{z}=\frac{\left(1-\underline{b}_{p}\right)^{\prime} A\left(\underline{R}-\underline{b}_{p} R_{p}\right)}{\left(1-\underline{b}_{p}\right)^{\prime} A\left(1-\underline{b}_{p}\right)}
$$

where $A$ is an arbitrary weighting matrix.

The generalized least squares estimator of $R_{z}$ is obtained 
by replacing $A$ with the inverse of the sample residual covariance matrix $S_{p}$. This estimator is also the average return of portfolio $\mathrm{z}$ in Figure 1. However, calculation of this estimator is not possible when $\mathrm{N}$ is greater than $\mathrm{T}$. Other estimators like ordinary and weighted least squares converge to $R_{z}$ in large samples when $p$ is efficient but generally converge to different numbers when $p$ is inefficient. That is, in large samples, the ordinary and weighted least squares portfolios lie on the line above $\mathrm{z}^{*}$ for efficient portfolios like $\mathrm{p}^{*}$ and are generally located at different points inside the parabola of minimum variance orthogonal portfolios in Figure 1 for inefficient portfolios like $\mathrm{p}$.

Portfolio $\mathrm{z}$ has a zero sample beta but will not have a zero population beta except by random chance. Risk premium estimates based on beta estimates suffer from the usual errorsin-variables bias induced by measurement error in the sample betas. Hence, the estimates of $R_{z}$ obtained from ordinary, weighted, and generalized least squares regressions are all biased downward in finite samples, biases which do, however, vanish in large samples. Two procedures have been employed to mitigate this problem-grouping and measurement error corrections. 
Grouping is a standard statistical solution to the errorsin-variables problem. Since Black, Jensen, and Scholes(1972) and Fama and MacBeth(1973), it has been common practice to form between ten and forty portfolios, often sorting by the sample betas from a previous period to improve the precision of the estimated zero beta rate. Portfolio betas have much smaller sampling errors than individual security betas and, hence, their use diminishes the errors-in-variables bias. The advantage of this procedure is its simplicity and the cost is the potential loss of information from grouping, particularly when testing asset pricing models.

An alternative approach involves attacking the measurement error problem more directly. The potential errors-in-variables bias in this estimator has three sources: the covariance between the sampling error in $\underline{b}_{p} R_{p}$ and $\left(1-\underline{b}_{p}\right)$, the difference between the sample variance of $\left(1-\underline{b}_{p}\right)$ and the sample variance of $\left(1-\beta_{p}\right)$, and potential dependence between the sampling errors in both $\underline{R}$ and $R_{p}$ and that in $\underline{b}_{p}$. Miller and Scholes(1972) provide an excellent discussion of this general problem in a related context.

The first two potential sources of errors-in-variables bias can be mitigated by using information on the sampling error in 
estimated betas. In particular, we can estimate the variance of the measurement error in sample betas under alternative statistical assumptions and correct least squares estimators accordingly. For example, $\left(1-\underline{b}_{p}\right)^{\prime} A\left(1-\underline{b}_{p}\right)-E\left[\left(\underline{b}_{p}-\beta_{p}\right)^{\prime} A\left(\beta_{p}-\underline{b}_{p}\right)\right]$ is an unbiased estimator of $\left(\underline{1}-\beta_{p}\right)^{\prime} A\left(1-\beta_{p}\right)$. Similarly, $\left(1-\underline{b}_{p}\right)^{\prime} A\left(R-\underline{b}_{p} R_{p}\right)-E\left[\left(\underline{b}_{p}-\beta_{p}\right)^{\prime} A\left(\beta_{p}-\underline{b}_{p}\right)\right] R_{p}$ is an unbiased estimator of $\left(1-\beta_{p}\right)^{\prime} A\left(\mathbb{R}-\beta_{p} R_{p}\right)$ ignoring possible dependence between the sampling errors in $\underline{R}$ and $R_{p}$ on the one hand and $\underline{b}_{p}$ on the other. Both bias corrections can be implemented given an unbiased estimator of $E\left[\left(\underline{b}_{p}-\beta_{p}\right)^{\prime} A\left(\beta_{p}-\underline{b}_{p}\right)\right]$ and the ratio of these two bias-corrected quantities yields an approximately unbiased estimate of $R_{z}$ (ignoring Jensen's inequality). See Litzenberger and Ramaswamy(1979), Shanken(1983), and Lehmann(1990) for further details.

The third potential bias arises from potential relations among the sampling errors in $\underline{R}, R_{p}$ and $\underline{b}_{p}$. The bias is usually small given symmetric return distributions (like the normal) which imply little dependence between first and second moments. However, it can be quite serious when returns are drawn from skewed distributions and is amplified when $\underline{b}_{p}$ is replaced by other sample moments such as the variance of returns, which is highly correlated with mean returns under 
skewness. The distributions of the returns of individual equity securities tend to be skewed sharply to the right while the returns of diversified portfolios tend to be symmetrically distributed so that grouping can mitigate this bias.

Most of the literature has assumed that returns are independently distributed over time and this suggests a simple palliative. Since Fama and MacBeth(1973) and Black and Scholes(1974), it has been common to estimate parameters like $\underline{b}_{\mathrm{p}}$ in one sample period and the returns of portfolio $z$ in a subsequent period. In a cross-sectional regression framework with no measurement error corrections, this procedure takes the form:

$$
R_{z t+1}=\frac{\left(\underline{l}-\underline{b}_{p t}\right)^{\prime} A_{t}\left(R_{t+1}-\underline{b}_{p t} R_{p t+1}\right)}{\left(1-\underline{b}_{p t}\right)^{\prime} A_{t}\left(l-\underline{b}_{p t}\right)}
$$

where all returns are for period $t+1$ and the subscript $t$ on an estimator means that it is based on data from period $t$ and earlier. The measurement errors in $A_{t}$ and $\underline{b}_{p t}$ are distributed independently of subsequent returns when returns are independently distributed over time. The expected return of portfolio $\mathrm{z}$ can then be measured by the sample mean of the actual portfolio returns $R_{z t+1}$ based on the estimates $A_{t}$ and $\underline{b}_{p t}$. Measurement error corrections can be applied as well. 
The actual returns of portfolio $\mathrm{z}$ can also be used to draw inferences about $R_{z}$. In particular, a natural estimator of the standard error of the mean return is the standard deviation of the portfolio return divided by the square root of T. This estimator is, in fact, biased in large samples even when returns are independently distributed over time but the asymptotic bias is seldom large in asset pricing applications. It provided an operational procedure for inference at a time when econometric theory was neither sufficiently well developed nor understood to provide all of the necessary asymptotic theory.

Consistent standard errors follow from now wellknown results from large sample theory. Let $\sqrt{\mathrm{T}}(\underline{\mathrm{d}}-\boldsymbol{\delta})$ be a random vector that converges in distribution to a normal random vector with mean zero and covariance matrix $\Delta$. Suppose we are interested in estimating a function $g(\delta)$ like a risk premium. A natural estimator of $g(\underline{\delta})$ is $g(\underline{d})$. Under suitable regularity conditions, $\sqrt{\mathrm{T}}(\mathrm{g}(\underline{\mathrm{d}})-\mathrm{g}(\boldsymbol{\delta}))$ converges in distribution to a normal random variable with mean zero and variance $g^{\prime}(\delta)^{T} \Delta g^{\prime}(\delta)$ where $g^{\prime}(\delta)$ is the first derivative of $g(\delta)$. The asymptotic variance can then be consistently estimated by replacing $g^{\prime}(\delta)^{T} \Delta g^{\prime}(\delta)$ with $g^{\prime}(d)^{T} D g^{\prime}(\underline{d})$ where $D$ is any consistent estimator of $\Delta$. Lehmann(1990) contains the relevant 
expressions for the standard errors of risk premiums in linear asset pricing models using this approach.

Researchers have also studied maximum likelihood estimators of zero beta rates assuming returns are normally and independently distributed over time. Many of the intuitions for the least squares estimator of the zero beta rate carry over to the maximum likelihood estimator because it is linear in the maximum likelihood estimator of the vector of asset betas. Kandel(1986) provides a detailed discussion of the geometry of the maximum likelihood estimator of the zero beta rate and Shanken(1986) provides useful computational results.

Zero beta rate and beta estimates can be viewed as generalized method of moments estimates based on the moment conditions $\mathrm{E}\left[\varepsilon_{\mathrm{pt}+1} R_{\mathrm{pt}+1}\right]=\mathrm{E}\left[\varepsilon_{\mathrm{pt}+1}\right]=\underline{0}$. The general problem of estimation and inference in asset pricing models can be cast in the generalized method of moments framework of Hansen(1982). To fix matters, let $Q_{t, 1}$ be parameterized as $Q_{t, 1}\left(\underline{x}_{t+1}, \mathcal{R}\right)$ where $\underline{x}_{t+1}$ is a vector of variables relevant for determining $Q_{t, 1}$ and $\rho$ is a $q \times 1$ vector of unknown parameters underlying the functional form for $Q(\bullet)$ (i.e., $\left(\varrho \in P \subset \Re^{q}\right)$. In addition, let $\underline{z}_{i t}$ be an $m_{i} \times 1$ vector of variables known at time $t$ (i.e., $\left.\underline{z}_{i t} \in I_{t}\right)$. Finally, let $\underline{h}_{i t+1}(\rho)$ denote the $m_{i} x 1$ vector 
$R_{i t+1} Q_{t, 1}\left(\underline{x}_{t+1}, \rho\right) \underline{z}_{i t-1}$ and let $\underline{h}_{t+1}(\mathcal{L})$ be the $M$ (i.e., the $\sum_{i=1}^{N} m_{i}$ ) vector obtained by stacking $\underline{h}_{i t+1}(\mathcal{Q})$ for $i=1, \ldots, N$. In the special case where $\underline{z}_{i t}=\underline{z}_{t} \forall i, \underline{h}_{t+1}(\mathcal{L})$ is given by $\underline{R}_{t+1} Q_{t, 1}\left(\underline{x}_{t+1}, \mathcal{R}\right) \otimes \underline{z}_{t-1}$ where $\otimes$ is the usual Kronecker product operator. Finally, assume that $\underline{h}_{t+1}(\mathcal{D})$ possesses a nonsingular population covariance matrix and that $E\left[\underline{h}_{t+1}(\mathcal{Q})\right]$ has full column rank.

Following Hansen and Singleton(1982), the rational expectations no-arbitrage asset pricing relation implies the vector moment condition $E\left[\underline{h}_{t+1}(\rho)\right]=\underline{0}$. Save for the choice of the appropriate variables and the functional form for $Q(\bullet)$, asset pricing models implicitly prescribe the econometric methods appropriate for their estimation-choose $\Omega$ to set the average value of $\underline{h}_{t+1}(\mathcal{Q})$ as close to zero as possible. Unfortunately, all such sample moments cannot be simultaneously set to zero when the number of nonredundant moment conditions $M$ exceeds the number of unknown parameters $\mathrm{q}$.

Accordingly, Hansen(1982) has suggested the generalized method of moments estimator $\underline{r}$ that minimizes the sample quadratic form based on a sample of $T$ observations on $\underline{R}_{t+1}$, $\underline{x}_{t+1}$, and $\underline{z}_{\mathrm{it}}:$ 


$$
\min _{\rho} \underline{h}_{\mathrm{T}}(\varrho)^{\prime} \mathrm{W}_{\mathrm{T}} \underline{\mathrm{h}}_{\mathrm{T}}(\varrho) ; \quad \underline{\mathrm{h}}_{\mathrm{T}}(\varrho)=\frac{1}{\mathrm{~T}} \sum_{\mathrm{t}=1}^{\mathrm{T}} \underline{\mathrm{h}}_{\mathrm{t}}(\rho)
$$

given a positive definite weighting matrix $\mathrm{W}_{\mathrm{T}}$ converging in probability to a positive definite limit $W$.

Large sample inference for $\underline{r}$ is straightforward and parallels the asymptotic standard error calculations sketched above. Under suitable regularity conditions, Hansen(1982) has shown that:

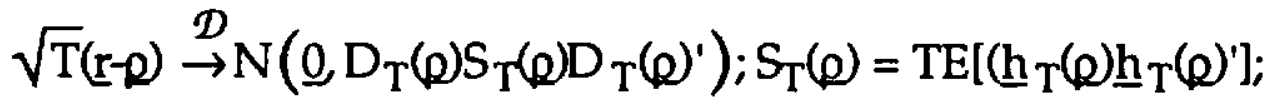

$$
\begin{aligned}
& \mathrm{D}_{\mathrm{T}}(\varphi)=\left[\mathrm{h}_{\mathrm{T}}(\varphi) \mathrm{W}_{\mathrm{T}} \underline{\mathrm{h}}_{\mathrm{T}}(\varphi)\right]^{-1} \underline{h}_{\mathrm{T}}(\rho) \mathrm{W}_{\mathrm{T}}
\end{aligned}
$$

where $\stackrel{\mathcal{D}}{\rightarrow}$ denotes convergence in distribution. Consistent standard error estimates can be calculated from this expression by replacing $\Omega$ with $\underline{r}$. Hansen(1982) showed that these standard errors are robust to both conditional heteroskedasticity and autocorrelation in large samples, a useful feature in the presence of time-varying expected returns.

Asymptotically, the optimal weighting matrix $\mathrm{W}_{\mathrm{T}}$ is proportional to $S_{T}(\mathcal{Q})^{-1}$. When $T$ exceeds $M$ and returns are independently distributed over time, the optimal weighting matrix can be consistently estimated by:

$$
\left.\mathrm{W}_{\mathrm{T}} \underline{\underline{r}}^{*}\right)=\left[\frac{1}{\mathrm{~T}} \sum_{\mathrm{t}=1}^{\mathrm{T}} \underline{\mathbf{h}}_{\mathrm{t}}\left(\mathbf{r}^{*}\right) \underline{\mathbf{h}}_{\mathrm{t}}\left(\mathbf{r}^{*}\right)^{\prime}\right]^{-1}
$$




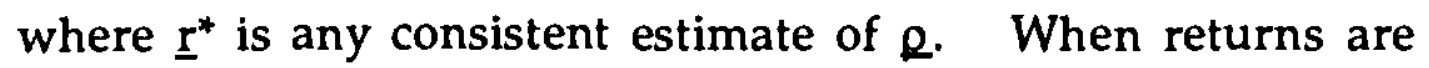
serially dependent, $W_{T}$ can be estimated by any consistent estimator of the spectral density of $\underline{h}_{t}(\rho)$ at frequency zero. See Hansen(1982) and Newey and West(1987) for further discussion.

However, this optimal weighting matrix generally cannot be estimated when $M$ is greater than $T$ since the usual estimators of $S_{T}(\mathcal{D})$ are then singular and, hence, noninvertible. Asymptotically less efficient choices for $W_{T}$ like the identity matrix (which is analogous to ordinary least squares) or the diagonal matrix consisting of the inverses of the sample variances of $\underline{h}_{t}\left(\underline{r}^{*}\right)$ (which is analogous to weighted least squares) can be employed instead. Alternatively, the $\mathrm{N}$ assets underlying the moment conditions can be grouped into a smaller number of portfolios and the number of moment conditions (i.e., the number of information variables $\underline{z}_{i t}$ ) can be limited so that the resulting weighting matrix is nonsingular.

\section{Testing}

Figure 1 also illustrates the basic principles of meanvariance efficiency tests. If a portfolio is mean-variance efficient like $\mathrm{p}^{*}$, all of its associated zero beta portfolios which cost a dollar have the same expected return as portfolio $z^{*}$. 
Hence, all costless zero beta portfolios associated with $\mathrm{p}^{*}$ have zero mean returns. On the other hand, an inefficient portfolio like $\mathrm{p}$ has associated zero beta portfolios that cost a dollar at all levels of mean return. In Figure 1, this is the set of minimum variance orthogonal portfolios and all of the portfolios that lie inside this parabola. Consequently, costless zero beta portfolios need not have zero expected returns when $p$ is not mean-variance efficient. Intuitively, mean-variance efficiency tests ask whether particular costless zero beta portfolios have zero expected returns.

The algebraic embodiment of this intuition is straightforward. Consider the unconditional expected return relation for individual securities:

$$
E\left[R_{i t+1}\right]=\alpha_{i p}+\left(1-\beta_{i p}\right) R_{z}+\beta_{i p} E\left[R_{p t+1}\right]
$$

The parameter $\alpha_{\mathrm{ip}}$ is the expected return of the portfolio formed by buying $\$ 1$ of security $i$, selling short $\$\left(1-\beta_{i p}\right)$ of portfolio $z$, and selling short $\$ \beta_{i p}$ of portfolio $p$. This portfolio is costless (since the long position is financed by the short positions) and has a zero beta (since the positions in portfolios $\mathrm{p}$ and $z$ hedge the beta risk). Accordingly, the expected return $\alpha_{i p}$ of this zero net investment, zero beta portfolio should be zero if $\mathrm{p}$ is an efficient portfolio. All such portfolios for each of the $\mathrm{N}$ 
securities should then have zero expected returns.

In the absence of specific alternative hypotheses, a statistician would naturally test the joint hypothesis that the $\mathrm{N}$ $\alpha_{i p}$ 's are all equal to zero against the vague alternative hypothesis that some or all of them are nonzero. This hypothesis has a simple portfolio interpretation: that all portfolios of the costless zero beta portfolios with expected return $\alpha_{i p}$ have expected returns of zero. Such tests implicitly search the $\mathrm{N}$ dimensional space of potential costless zero beta portfolios for at least one with a nonzero expected return.

To simplify matters, suppose that $R_{z}$ is known as would be the case if portfolio $\mathrm{z}$ were an observed riskless asset. Sample mean returns then satisfy:

$$
R_{i}=a_{i p}+\left(1-b_{i p}\right) R_{z}+b_{i p} R_{p}
$$

where $a_{i p}$ is the sample analogue of $\alpha_{i p}$. If excess returns are jointly normally and independently distributed over time, the joint null hypothesis that the $N \alpha_{i p}$ 's are all zero can be tested with the $\mathrm{T}^{2}$ statistic:

$$
\mathrm{T} \frac{\underline{\mathrm{a}}_{\mathrm{p}}{ }^{\prime} \mathrm{S}_{\mathrm{p}}^{-1} \underline{\mathrm{a}}_{\mathrm{p}}}{1+\frac{\left(\mathrm{R}_{\mathrm{p}}-\mathrm{R}_{\mathrm{z}}\right)^{2}}{\mathrm{~s}_{\mathrm{p}}^{2}}} \sim \mathrm{T}^{2}(\mathrm{~N}, \mathrm{~T}-2)
$$

where $s_{p}^{2}$ is the sample variance of the returns of portfolio $p$. The product of (T-N-1)/NT and the $\mathrm{T}^{2}$ statistic follows an $\mathrm{F}$ 
distribution with $\mathrm{N}$ and T-N-1 degrees of freedom. This is just a standard $\mathrm{F}$ test for the hypothesis that the intercepts in a multivariate regression are all equal to zero which is discussed at some length in MacKinlay(1987) and Gibbons, Ross, and Shanken(1989).

Large values of $\underline{\alpha}_{p} \Sigma_{p}^{-1} \underline{\alpha}_{p}$ make large values of $\underline{a}_{p}{ }^{\prime} S_{p}^{-1} \underline{a}_{p}$ more probable, increasing the likelihood of rejection of the null hypothesis of efficiency. The circumstances in which this occurs also have a portfolio interpretation: $\underline{\alpha}_{p}{ }^{\prime}{ }_{p}^{-1} \underline{\alpha}_{p}$ is the largest squared Sharpe ratio (i.e., ratio of squared mean to variance) of all costless zero beta portfolios since all minimum variance, zero net investment, zero beta portfolios have weights proportional to $\Sigma_{\mathrm{p}}^{-1} \underline{\alpha}_{\mathrm{p}}$. In the absence of a specific alternative hypothesis, it makes sense to examine the costless zero beta portfolio with the highest sample ratio of squared mean to variance.

This observation suggests that tests against vague alternatives will have low power unless portfolio $\mathrm{p}$ misprices many securities. Put differently, $\underline{\alpha}_{p}{ }^{\prime} \Sigma_{p}^{-1} \underline{\alpha}_{p}$ is smaller than $\underline{\alpha}_{p}{ }^{\prime} \underline{\alpha}_{p}$ divided by the smallest eigenvalue of $\Sigma_{p}$. Unless $\Sigma_{p}$ is nearly singular, $\underline{\alpha}_{p} \Sigma_{p}^{-1} \underline{\alpha}_{p}$ will be small if the sum of squared $\alpha_{i p}$ 's is small. Unfortunately, $\underline{\alpha}_{p}{ }^{\prime}{ }_{p}^{-1} \underline{\alpha}_{p}$ must be very large in 
the presence of many assets to yield probable rejections since the $\mathrm{T}^{2}$ statistic implicitly searches in $\mathrm{N}$ dimensions for costless zero beta portfolios with nonzero mean returns.

When the known value of $R_{z}$ is replaced by a generalized least squares version of $r_{z}$ in the $T^{2}$ statistic, the estimated $a_{i p}$ 's behave like the intercepts from the regression of $\underline{R}_{t+1}-1 R_{z}$ on $R_{p t+1}-R_{z}$ in large samples. Hence, the $T^{2}$ statistic can be used to test the null hypothesis of efficiency in large samples after replacing $\mathrm{N}$ with $\mathrm{N}-1$ to allow for the degree of freedom lost in the estimation of $R_{z}$. Shanken $(1985,1986)$ argued convincingly for the finite sample relevance of this asymptotic approximation. Related tests like likelihood ratio tests have poor finite sample properties, a fact documented in Stambaugh(1982), Amsler and Schmidt(1985), and MacKinlay(1987).

The transition from the zero beta CAPM to the general model involves the passage from independently and identically distributed to possibly serially correlated returns. The analysis of tests of general asset pricing relations against vague alternative hypotheses parallels that for the efficiency of portfolio $\mathrm{p}$. In the generalized method of moments framework of Hansen(1982) and Hansen and Singleton(1982), the rational 
expectations no-arbitrage asset pricing relation implies the vector moment condition $E\left[\underline{h}_{t+1}(\rho)\right]=\underline{0}$. When the optimal generalized method of moments estimator of $R$ is employed (i.e., when the weighting matrix $W_{T}$ is proportional to $\left.S_{T}(\ell)^{-1}\right)$, the null hypothesis can be tested against the vague alternative hypothesis $E\left[\underline{h}_{t+1}(\rho)\right] \neq \underline{0}$ since:

$$
\mathrm{T} \underline{\mathrm{h}}_{\mathrm{T}}(\mathrm{r})^{\prime} \mathrm{S}_{\mathrm{T}}(\underline{\mathrm{r}})^{-1} \underline{\mathrm{h}}_{\mathrm{T}}(\mathrm{r}) \stackrel{\mathcal{D}}{\rightarrow} \chi^{2}(\mathrm{M}-\mathrm{q})
$$

in large samples.

None of this testing apparatus is applicable when $N$ or $M$ are greater than T. Since this is the case in financial market data for most countries, one must either place arbitrary restrictions on the asset menu or test asset pricing relations against particular alternative hypotheses. In practice, the latter option is generally taken in the literature.

One common strategy is to group the available universe of securities into a smaller number of portfolios. The asset pricing model is then being tested against an alternative hypothesis implicit in the choice of grouping variable. For example, the implicit alternative hypothesis is that the $\alpha_{\text {ip }}$ 's of individual securities are systematically related to their betas when researchers group stocks based on their estimated betas in a previous period to facilitate estimation of zero beta rates. 
Grouping characteristics employed in the literature include firm size, dividend yield, price-earnings ratio, market-to-book value, previous period returns, and residual risk. Curiously, grouping strategies based on previous period $\alpha_{i p}$ estimateswhich would yield powerful tests when $\alpha_{\text {ip }}$ values persistgenerally have not been employed in the literature (see Lehmann(1988) for an exception). All of the testing apparatus developed above can be applied so long as the number of grouped portfolios or moment conditions is smaller than $\mathrm{T}$.

The other strategy is to test explicitly an asset pricing relation against a specific alternative hypothesis. Such tests involve estimating risk premiums for security characteristics when theory predicts that the risk premiums are zero. For example, if $\underline{z}_{i t}$ is a vector of characteristics known at time $t$, the mean-variance efficiency of portfolio $\mathrm{p}$ can be tested in the expected return model:

$$
E\left[R_{i t+1}\right]=\alpha_{i p}^{*}+\left(1-\beta_{i p}\right) R_{z}+\beta_{i p} E\left[R_{p t+1}\right]+\underline{z}_{i t}^{\prime} \gamma
$$

where the null hypothesis is that $q$ equals zero. Similarly, the parameter vector $\Omega$ in the generalized method of moments framework can be expanded to include a vector of risk premiums $\boldsymbol{y}$ for $\underline{z}_{i t}$ in the alternative model:

$$
E\left[\left(R_{i t+1} Q_{t, 1}\left(\underline{x}_{t+1}, Q\right)-1\right) \underline{z}_{i t}\right]=\boldsymbol{x}
$$


where the asset pricing model can be tested with the large sample $\chi^{2}$ statistic for the hypothesis that $\chi$ equals zero. Neither kind of test requires that $\mathrm{T}$ exceeds $\mathrm{N}$ or $\mathrm{M}$.

This approach permits the use of large cross-sections in efficiency tests which can dramatically increase their power. Large samples of securities make precise estimation of the covariance between security returns and characteristics more likely. However, researchers do often understate the pretest bias associated with the choice of particular alternative hypotheses, both in this strategy and in the grouping approach. In statistical jargon, the size of the resulting tests is typically overstated since the characteristics were chosen because of their estimated correlations with returns. The issues associated with pretest bias and the size of tests is discussed extensively in Lo and MacKinlay(1990). See Lehmann(1988) for an approach which largely avoids this pretest bias.

These specific alternative hypotheses take the form of positing variables that help explain expected returns when theory predicts they should not. In some cases, variables are selected by considering what variables should account for expected returns if the underlying assumptions of the asset pricing model-no frictions, no arbitrage, rational expectations, 
and the model for $Q_{t, 1}$ or the identity of portfolio $p$-are false. Nevertheless, the identification of nonzero risk premiums associated with theoretically irrelevant variables seldom suggests which of these joint hypotheses failed. In these circumstances, researchers typically look in the direction of improved models for $Q_{t, 1}$ or portfolio $p$. Future research may search more actively in other directions such as imperfect liquidity (i.e., failure of the no frictions assumption) or irrational beliefs (i.e., fads and fashions).

Finally, the best estimation procedures under the null hypothesis may not yield the most powerful tests under the alternative hypothesis. Similarly, particular alternative hypotheses might reduce the efficiency of risk premium estimators but potentially improve the power of the resulting tests. Put differently, data choices greatly affect the power of tests.

\section{Data}

While rational no-arbitrage models make sharp predictions, they leave open several measurement issues and data analytic choices. In particular, the preceding analysis took the asset menu, the model for $Q_{t, 1}$ or the a priori identification of portfolio $\mathrm{p}$ (and, perhaps, portfolio $\mathrm{z}$ ), and the information 
variables $\underline{z}_{i t} \in I_{t}$ as given. This section discusses questions about regarding the measurement of the relevant economic quantities as well as some pertinent features of U. S. data on asset prices.

Modern asset pricing relations tell researchers what to measure-the state price density $Q_{t, 1}$ or portfolio $p$. Particular models even indicate how to measure these quantities. For example, $Q_{t, 1}$ is proportional to the growth rate of aggregate consumption in the continuous time CCAPM and portfolio $p$ is the market portfolio of all risky assets in the CAPM.

Data analysts always face the possibility that important variables are measured with error and financial economists are no exception. In linear models like the time invariant beta pricing model or the continuous time CCAPM, classical measurement error in $Q_{t, 1}$ or the return of portfolio $p-$ that is, mean zero measurement error uncorrelated with asset returns-causes no problems in principle save for inefficiency in the parameter estimates. For example, such errors in measuring aggregate consumption growth do not bias estimates of its covariances with asset returns, the relevant parameters for this model.

Roll's (1977) critique can be read as a belief that 
measurement error correlated with returns is likely to be the rule rather than the exception in asset pricing applications. The particular focus of Roll's critique-the zero beta CAPMimplies that the market portfolio of all risky assets is meanvariance efficient. Tests of the zero beta CAPM typically examine whether proxies for the market portfolio such as equally weighted or value weighted indices of New York and American Stock Exchange stocks are mean-variance efficient. These tests provide no information about the efficiency of the market portfolio without a model linking the proxy and the unobservable market portfolio. Put differently, measurement error in aggregate wealth is likely to be correlated with asset returns. Similar problems afflict consumption measures when consumer durables yield unobservable consumption service flows that are likely to be correlated with asset returns.

There have been several responses to the Roll critique. Two reactions are conventional. One is testing the robustness of conclusions to the choice of proxies for portfolio $p$ or $Q_{t, 1}$. For example, it is common practice to use several proxies for aggregate consumption growth in tests of the CCAPM. Similarly, Stambaugh(1982) tested the sensitivity of tests of the CAPM to alternative proxies for the market portfolio. Second, 
researchers are more careful in stating precisely what theory is being tested. The literature now abounds with cautious statements about testing a particular implementation of a theory or testing the mean-variance efficiency of a particular portfolio rather than the CAPM.

More substantively, attention is now fixed on models that provide a framework for measuring portfolio $p$ or $Q_{t, 1}$. Prior to the Roll critique, Jensen(1969) and Miller and Scholes(1972) argued that CAPM tests using an equallyweighted index of many assets as a proxy for the market portfolio were joint tests of the CAPM and the hypothesis that the CAPM residuals could be diversified away in large portfolios (termed the single index market model). The APT built on this notion of diversifiable risk since well-diversified portfolios perfectly mimic the underlying common factors from multiple factor models in large cross-sections, yielding an obvious measurement strategy. Similarly, specific models have been proposed linking consumer durable purchases to consumption service flows. In addition, Kandel and Stambaugh(1987) and Shanken(1987) have shown how to test the joint hypothesis that a given model is true and some proxy for $\mathrm{p}$ has a given correlation with its true unobserved 
counterpart.

The choice of asset menu is less an option for the researcher than a constraint imposed by the financial markets that exist and the availability of data from them. The previous section emphasized the problems that arise when $\mathrm{N}$ exceeds $\mathrm{T}$. A more serious problem is that many countries do not have well-developed capital markets and even those that do contain many assets that are not traded in an organized (and easily recorded) fashion. A more complete theory of finance would account for both the existence and absence of different financial institutions across countries and assets but it is fair to say that such a theory is largely in the domain of future research.

Hence, a major empirical issue is asset coverage. There are data on many but not all assets in a few countries and spottier coverage in other countries. For example, there is high quality data on listed common stocks, government bonds, and futures contracts in the U. S. and comparable data for shorter periods in the United Kingdom and Japan. However, markets for the easy trading of most capital assets simply do not exist in most less developed countries and even the data for Common Market countries is somewhat sketchy, although this may change in the future. Some assets simply are not traded in 
liquid markets like corporate bonds, bank loans, human capital, and many forms of physical capital and real estate.

Coverage and imperfect asset markets are often troublesome issues for equilibrium theories like the CAPM. They are frequently less problematic for no-arbitrage models like the APT since such models typically apply to subsets of assets that satisfy the perfect markets assumption even when there are other assets that do not. Similarly, such problems can often be avoided in equilibrium asset pricing models with particular stochastic process assumptions. For example, Grossman and Shiller(1982) show that nontraded assets pose no problems for the continuous time CCAPM when instantaneous household consumption growth rates and asset returns jointly follow diffusion processes.

Another choice confronting the researcher is the choice of observation interval. Except for continuous time models, asset pricing models do not specify the decision intervals of investors. Accordingly, there is no a priori reason to think that investors make portfolio decisions on the daily, weekly, monthly, or annual bases implicitly assumed in most empirical applications. Jensen(1969) showed that the measurement interval was irrelevant in time invariant beta pricing models 
with are log-normal returns but temporal aggregation remains a problem in more general settings. See Grossman, Melino, and Shiller(1989) and Breeden, Gibbons, and Litzenberger(1989) for a discussion of temporal aggregation issues in continuous time asset pricing models.

Researchers must also choose the instruments $\underline{z}_{i t}$ that facilitate estimation and testing of asset pricing models. Early evidence suggested that past prices were not useful in predicting asset returns and thus much of the literature did not employ prior period instruments. There are now two kinds of commonly employed instruments-security characteristics and selected time series variables. While such variables are sometimes suggested by particular asset pricing models or alternative hypotheses, chosen instruments are generally the result of extensive prior data searches. See Lo and MacKinlay(1990) for further discussion.

There are some stylized facts about the behavior of asset returns that are important for both estimating and testing of asset pricing relations. In particular, the returns of long-lived assets like stocks and bonds are highly volatile in the short run. In terms of the moments that are relevant for many asset pricing models, this means that second moments like variances 
and covariances are typically precisely estimated while mean returns are usually estimated imprecisely, even over long time periods. In addition, there are well-measured, predictable changes in the short run volatility in asset returns which both provide the opportunity to estimate models of conditional heteroskedasticity and require appropriate inference procedures.

The imprecision of mean estimates suggests there may be a huge cost to specifying portfolio $\mathrm{p}$ a priori when estimating asset pricing relations. For example, an explicit model of $Q_{t, 1}$ (without nonclassical measurement error) and identification of $R_{z t+1}$ with a measured riskless rate completely avoid the need to estimate mean returns since $E\left[R_{p t+1} \mid I_{t}\right]$ equals $E\left[Q_{t, 1} \mid I_{t}\right]\left[1-\operatorname{Cov}\left(R_{p t+1}, Q_{t, 1} \mid I_{t}\right)\right]$, which ought to be measured well due to the volatility of asset returns. The covariance term is a function of risk aversion parameters in most equilibrium models and, hence, the resulting magnitude of estimated risk aversion provides an additional check on the plausibility of the model. In addition, the imprecision of mean estimates suggests that power is likely to plague efficiency tests in the absence of $a$ priori knowledge of variables that are correlated with population mean returns. 
The degree to which returns are predictable is important for the estimation and testing of intertemporal asset pricing models. Short run return predictability is generally both economically small and precisely measured, although the weekly returns of small firm portfolios exhibit substantial autocorrelation. The evidence on long run return predictability is considerably more controversial. The long run evidence remains inconclusive in large part because much of it comes from the Great Depression. Accordingly, precise estimation of intertemporal asset pricing models with time varying expected returns may be problematic even if they are true.

Finally, prices are typically measured well in financial market data while quantities are often measured poorly. For example, most equilibrium models imply that $Q_{t, 1}$ is a function of the growth rate of aggregate consumption services while consumption expenditures are the variable that is measured with much error. In fact, the theory of finance is primarily a theory of prices and not quantities partly because finance is data driven and prices are the data that are well measured.

High quality transactions data on stock and bond transactions are becoming available for U. S., European, and Japanese markets. Accordingly, theory and evidence regarding 
the volume of trade are central to the current research agenda in finance. This, too, is problematic since theories typically relate price fluctuations to the volume of informed trading and actual volume includes the trades of both informed and uninformed investors. Hence, much current research links volume and volatility on the hypothesis that volatility in large part reflects the trading of informed investors.

\section{Empirical Evidence}

This entry has provided a reasonably detailed description of the methods employed to estimate and test asset pricing theory. This section briefly describes the current empirical status of some mainstream asset pricing models. The discussion is brief on the hypothesis that the methodological contributions described earlier are more lasting.

The empirical literature on the CAPM went through two distinct phases. Early research concentrated on methodological developments and the exploration of alternative CAPM formulations. Later research revolved around the discovery of numerous 'anomalies'-security characteristics or calendar effects that helped explain average security returns after controlling for risk with estimated security betas. Perhaps accidentally, this second phase roughly 
coincided with the publication of Roll's (1977) critique.

There was little credible empirical evidence against the CAPM in the early literature. Variables like dividend yield, squared beta, and residual risk proved incapable of explaining the mean returns of grouped equity portfolios after risk adjustment using betas from an equally-weighted portfolio of New York Stock Exchange stocks as a proxy for the market portfolio. In fact, the main empirical observation was that the zero beta rate $R_{z}$ appeared to exceed the riskless rate, the value predicted by the Sharpe-Lintner-Mossin version of the CAPM.

Subsequently, substantial evidence against the CAPM arose in the form of empirical anomalies. New variables like firm size, price-earnings ratio, market-to-book value, and previous period returns helped account for risk-adjusted equity returns. Calendar effects - the January, week of the month, day of the week, and hour of the day effects-proved hard to rationalize in frictionless, no-arbitrage models in general and in the CAPM in particular. New statistical procedures employing individual securities instead of grouped portfolios found significant dividend yield and residual risk effects. In addition, the inclusion of small stocks amplified many of these effects.

While empirical tests of the APT also went through 
several phases, a more useful distinction involves the nature of the empirical implementation. One class of implementations identifies factors from the covariance structure of returns using statistical procedures like maximum likelihood factor analysis or principal components. A second strategy is to prespecify the factors a priori as either the growth rates of macroeconomic variables or the returns of particular assets or portfolios, an approach also susceptible to pretest bias. Finally, some studies prespecify instead security characteristics presumed to reflect the security correlations (i.e., betas) with the common factors. What are called anomalies in the CAPM have recently become 'prespecified betas' in APT implementations.

Loosely speaking, APT models better account for expected equity returns than CAPM implementations. There is little evidence of pronounced dividend yield or residual risk effects in the first two kinds of APT applications and the size and price-earnings ratio effects are much smaller. Of course, APT models that use security characteristics identified as CAPM anomalies as prespecified betas provide only self-referential 'explanations' of CAPM anomalies. In addition, CAPM betas seldom help explain average equity returns after APT risk adjustments. Unlike the CAPM, the pricing intercepts in APT 
applications are typically close to the riskless rate.

Finally, intertemporal and consumption-based models have not provided a satisfactory account of mean equity returns. Such models typically fail simple tests-like accounting for the cross-sectional variation in average industry portfolio returns-that are easily passed by APT and CAPM implementations. Similarly, consumption betas typically fail to help explain cross-sectional variation in mean equity returns after CAPM or APT-style risk adjustments. Intertemporal models have not yet confronted the more rigorous challenge of explaining the expected returns of small, high earnings yield, zero dividend, high volatility firms. However, much of this literature has focussed on the inability of equilibrium intertemporal models to explain the equity premium and riskfree rate puzzles, not on their ability to explain relative equity prices.

In fact, the distinctions among the CAPM, APT, and intertemporal theories have blurred in practice. Quantitative portfolio managers use multiple factor models irrespective of the labels they attach to them. In academic applications, it is now commonplace to assume that returns are generated by some collection of factors which may be observed or 
unobserved and have time-varying or time invariant risk premiums. These multifactor models are generally consistent with most modern asset pricing models save for the question of whether their residuals can be diversified away in large crosssections. Since empirical implementations typically employ grouped portfolios, the cross-sectional diversifiability of the residuals is not testable so that the distinction among models is largely semantic.

This is unsurprising-all multibeta models can be collapsed into single beta representations. As shown in the theory section, all rational no-arbitrage asset pricing models imply the existence of a (conditionally) mean-variance efficient portfolio. Accordingly, much of the heat regarding the comparative virtues and flaws of alternative models-which occupied much of the literature in the 1970s-has largely dissipated.

More importantly, this observation suggests the empirical utility of no-arbitrage models. They provide a useful framework within which to organize and generate facts about the covariation and variation of asset returns, facts that are surely relevant for many plausible asset pricing models. Similarly, different intuitions about the empirical failures of 
asset pricing models can easily be incorporated into the noarbitrage framework. Accordingly, empirical research will proceed on a broad front for the foreseeable future. Asset pricing models, models for portfolio $p$ or $Q_{t, 1}$, will continue to improve. In addition, researchers will explore the implications of alternative models for beliefs (i.e., fads) and frictions (i.e., taxes, short sales constraints, and market microstructure issues). 


\section{Bibliography}

Amsler, Christine E. and Peter Schmidt, 1985, "A monte carlo investigation of the accuracy of multivariate CAPM tests," Lournal of Financial Economics 14, pp. 359-376.

Black, Fischer, Michael C. Jensen, and Myron Scholes, 1972, "The capital asset pricing model: some empirical tests" in Michael C. Jensen, ed., Studies in the Theory of Capital Markets (New York: Praeger).

- and Myron Scholes, 1974, "The effects of dividend yield and dividend policy on common stock prices and returns," Journal of Financial Economics 1, May, pp. 1-22.

Breeden, Douglas T., Michael R. Gibbons, and Robert H. Litzenberger, 1989, "Empirical tests of the consumptionoriented CAPM." Lournal of Finance 44, pp. 231-262.

Chamberlain, Gary and Michael Rothschild, 1983, "Arbitrage and mean-variance analysis on large asset markets," Econometrica 51, pp. 1281-1304.

Chan, K. C., 1988, "On the contrarian investment strategy," lournal of Business 61, pp. 147-163.

Chen, Nai-fu, Richard W. Roll, and Stephen A. Ross, 1986, "Economic forces and the stock market," Lournal of Business 59, pp. 383-403.

Connor, Gregory and Robert A. Korajczyk, 1988, "Risk and return in an equilibrium APT: application of a new test methodology," Iournal of Financial Economics 2, pp. 255-289.

De Bondt, Werner F. M. and Richard Thaler, 1985, "Does the stock market overreact?" Iournal of Finance 40, pp. 793805. 
- , 1987, "Further evidence on investor overreaction and stock market seasonality," \ournal of Finance 42, pp. 557-581.

Epstein, Larry G. and Stanley E. Zin, 1991, "Substitution, risk aversion, and the temporal behavior of consumption and asset returns: an empirical analysis," Lournal of Political Economy 96, pp. 263-286.

Fama, Eugene F., 1970, "Efficient capital markets: a review of theory and empirical work," Iournal of Finance 25, pp. 383-417.

- and James D. MacBeth, 1973, "Risk, return, and equilibrium: empirical tests," Lournal of Political Economy 81, pp. 607-636.

- and G. William Schwert, 1977, "Asset returns and inflation," Iournal of Financial Economics 5, pp. 115-146.

French, Kenneth R., 1980, "Stock returns and the weekend effect," Iournal of Financial Economics 8, pp. 55-69.

Gibbons, Michael R., 1982, "Multivariate tests of financial models: a new approach," Lournal of Financial Economics 10, pp. 3-28.

-, Stephen A. Ross, and Jay Shanken, 1989, "A test of the efficiency of a given portfolio," Econometrica 57, pp. 1121-1152.

Grossman, Sanford J. and Robert J. Shiller, 1982, "Consumption correlatedness and risk measurement in economies with non-traded assets and heterogeneous information," Iournal of Financial Economics 10, pp. 195-210.

Grossman, Sanford J., Angelo Melino; and Robert J. Shiller, 1987, "Estimating the continuous-time consumptionbased asset pricing model," Iournal of Business and Economic Statistics 5, pp. 315-327. 
Hansen, Lars P., 1982, "Large sample properties of generalized method of moments estimators," Econometrica 50, pp. 1029-54.

- and Kenneth J. Singleton, 1982, "Generalized instrumental variables estimation of nonlinear rational expectations models," Econometrica 50, pp. 1269-1286.

- and Kenneth J. Singleton, 1983, "Stochastic consumption, risk aversion, and the temporal behavior of asset returns," Iournal of Political Economy 91, pp. 249-265.

- and Ravi Jagannathan, 1989, "Implications of security market data for models of dynamic economies," Lournal of Political Economy 99, pp. 225-262.

Jegadeesh, Narasimhan, 1990, "Evidence of predictable behavior of security returns," Iournal of Finance 45, pp. 881-898.

Jensen, Michael C., 1969, "Risk, the pricing of capital assets, and the evaluation of investment portfolios," Iournal of Business 42, pp. 389-416.

Jobson, J. D. and Bob M. Korkie, 1982, "Potential performance and tests of portfolio efficiency," Journal of Financial Economics 10, pp. 433-466.

Kandel, Shmuel, 1984, "The likelihood ratio test statistic of mean variance efficiency without a riskless asset," Iournal of Financial Economics 13, pp. 575-592.

—, 1986, "The geometry of the maximum likelihood estimator of the zero-beta return," Lournal of Finance 41, pp. 339346.

- and Robert F. Stambaugh, 1987, "On correlations and inferences about mean-variance efficiency," Lournal of Financial Economics 18, pp. 61-90. 
Lehmann, Bruce N., 1990, "Residual risk revisited," Lournal of Econometrics 45, pp. 71-97.

—, 1988, "Mean-variance efficiency tests in large crosssections," unpublished manuscript, Graduate School of Business, Columbia University.

- , 1990, "Fads, martingales, and market efficiency," Quarterly Lournal of Economics 105, pp. 1-28.

- and David M. Modest, 1988, "The empirical foundations of the arbitrage pricing theory," Iournal of Financial Economics 21, pp. 213-254.

Litzenberger, Robert and Krishna Ramaswamy, 1979, "The effects of personal taxes and dividends on capital asset prices," Lournal of Financial Economics 7, pp. 163-195.

Lo, Andrew W. and A. Craig MacKinlay, 1990, "Data snooping biases in tests of financial asset pricing models," Review of Financial Studies 3, pp. 431-467.

MacKinlay, Craig, 1987, "On multivariate tests of the CAPM," Iournal of Financial Economics 18, pp. 341-372.

Merton, Robert C., 1980, "On estimating the expected return on the market," Journal of Financial Economics 8, pp. 323361.

Miller, Merton H. and Myron Scholes, 1972, "Rates of return in relation to risk: a reexamination of some recent findings" in Michael C. Jensen (ed.), Studies in the Theory of Capital Markets (New York: Praeger).

Newey, Whitney and Kenneth West, 1987, "A simple, positive semi-definite, heteroskedasticity and autocorrelation consistent covariance matrix," Econometrica 55, 703-708. 
Roll, Richard W., 1977, "A critique of the asset pricing theory's tests-part I: on past and potential testability of the theory," Iournal of Financial Economics 4, pp. 129-176.

-, 1979, "Testing a portfolio for ex ante mean variance efficiency" in Edwin E. Elton and Martin J. Gruber, eds., Portfolio Theory, Twenty Five Years After (New York: North- Holland).

- 1980, "Orthogonal portfolios," Lournal of Financial and Quantitative Analysis 15, pp. 1005-1023.

- 1985, "A note on the geometry of Shanken's CSR $\mathrm{T}^{2}$ test for mean-variance efficiency," Lournal of Financial Economics 14, pp. 349-358.

Rosenberg, B., Kenneth Reid, and Ronald Lanstein, 1985, "Persuasive evidence of market inefficiency," Iournal of Portfolio Management 12, pp. 9-16.

Ross, Stephen A., 1978, "A simple approach to the valuation of risky streams," Lournal of Business 51, pp. 1-40.

Rothschild, Michael, 1986, "Asset pricing theories" in Walter P. Heller, Ross M. Starr, and David A. Starrett, (eds.), Uncertainty, Information, and Communication: Essays in Honor of Kenneth I. Arrow (Cambridge, England: Cambridge University Press).

Rubinstein, Mark, 1976, "The valuation of uncertain income streams and the pricing of options," Bell Journal of Economics and Management Science 7, pp. 407-425.

Shanken, Jay, 1983, "An asymptotic analysis of the traditional risk return model," School of Business Administration, University of California, Berkeley.

- 1985, "Multivariate tests of the zero beta CAPM," Iournal of Financial Economics 14, pp. 327-348. 
- 1986, "Testing portfolio efficiency when the zero beta rate is unknown," Journal of Finance 41, pp. 269-76.

- 1987, "Multivariate proxies and pricing relations: living with the Roll critique," Journal of Financial Economics 18, pp. 91-110.

Sharpe, William F., 1985, "Factor models, CAPMs, and the APT," Lournal of Portfolio Management , pp. 21-25.

Singleton, Kenneth J., 1990, "Specification and estimation of intertemporal asset pricing models" in Benjamin Friedman and Frank Hahn (eds.), Handbook of Monetary Economics (Amsterdam: North-Holland).

Stambaugh, Robert F., 1982, "On the exclusion of assets from tests of the two-parameter model: a sensitivity analysis," Journal of Financial Economics 10, pp. 237-268.

Sweeney, Richard and Arthur D. Warga, 1986, "The pricing of interest rate risk: evidence from the stock market," Lournal of Finance 41, pp. 393-410. 